\title{
Health, Human Rights, and Ethics
}

\author{
ERIC STOVER and HARVEY WEINSTEIN
}

Public health and human rights are complementary-and, at times, conflicting-approaches to protecting and promoting human well-being and dignity. Public health addresses the needs of populations and seeks, through intervention and education, to prevent the spread of disease. Enshrined in international law, human rights describe the obligations of governments to safeguard their citizenry from harm and to create conditions where each individual can achieve his or her full potential. Human rights norms lie at the core of public health theory and practice, and their enforcement can help to ensure an equitable distribution of health resources.

Bioethics cuts through both of the fields of public health and human rights to address how health practitioners must respond when the health and well-being of vulnerable people is under threat. Why is it that the field of bioethics has developed on a seemingly different trajectory than that of public health and human rights over the past 50 years? Are there points where these three fields could now converge? Do such concepts as beneficence or informed consent belong in a broader discussion of the rights of peoples, especially given the recent controversy surrounding AIDS research in developing countries? Similarly, what light could bioethicists shed on issues such as: access to healthcare, clean water, food, and sewage; discrimination in healthcare procedures; and women's rights, where the health of whole populations is at stake?

In this new column, we welcome a wide range of articles that explore the interrelationship between health and human rights, and between bioethics and human rights. Papers could address the human rights and ethical implications of biomedical and other human subject research; the ethical implications of economic disparity or other social impacts on health status; the application of the health and forensic sciences to investigation of human rights abuses; the impact of health policies on human rights; and issues of gender, health, and human rights. For the first paper, we have selected an inquiry into the forensic procedures and ethical dimensions of an international effort to identify the remains of thousands of men and young boys who were executed during the siege of the Bosnian town of Srebrenica in July, 1995. 